\title{
THE EFFECT OF CLEANING PROCEDURES ON THE BOND STRENGTH OF CERAMIC SURFACES CONTAMINATED WITH SALIVA AND TRY-IN PASTE
}

\author{
Luiz H. Gonzaga ${ }^{1 a^{*}}$, Himanshu Arora ${ }^{1,2 b}$, William C. Martin ${ }^{1 c}$ \\ ${ }^{1}$ Center for Implant Dentistry, College of Dentistry, University of Florida, Gainesville, FL, USA \\ ${ }^{2}$ School of Dentistry and Oral Health, Griffith University, Gold Coast, Australia \\ ${ }^{a} D D S, M S$ \\ ${ }^{\mathrm{B} B D S}, \mathrm{MDS}, \mathrm{PhD}$ \\ 'DDS, MS, FACP
}

\begin{abstract}
DOI: https://doi.org/10.25241/stomaeduj.2019.6(1).art.2
Purpose of the study: To evaluate the effectiveness of different cleaning procedures on removing the saliva and try-in paste remnants from contaminated zirconia and lithium disilicate surfaces.

Material and Methods: Fifty samples of zirconia (IPS e.max ZirCAD) and 50 samples of lithium disilicate (IPS e.max CAD) were divided into 5 groups: Group 1 - No contamination with saliva and try-in paste (control); Group 2 - Contamination followed by rinsing with water; Group 3 - Contamination followed by cleaning with $\mathrm{NaOCL} 7 \%$ for 30 seconds; Group 4 - Contamination followed by cleaning with $\mathrm{H}_{3} \mathrm{PO}_{4} 35 \%$ for 30 seconds; Group 5 - Contamination followed by cleaning with Ivoclean for 30 seconds. Zirconium oxide cylinders were luted to the samples using Multilink Implant cement. After being stored for 24 hours in a deionized water bath at $37^{\circ} \mathrm{C}$, the samples were subjected to shear forces at a crosshead speed of $0.5 \mathrm{~mm} / \mathrm{min}$. ANOVA and Tukey's post-hoc test were used for statistical analysis.

Results: No significant differences were observed between various groups for zirconia samples with all cleaning protocols showing shear bond strengths similar to the control groups. Group 4 showed significant improvement in shear bond strength when compared to control $(p<0.05)$ for lithium disilicate samples.

Conclusions: Within the limitations of this study it could be said that the application of phosphoric acid for 30 seconds is effective to clean lithium disilicate samples contaminated with saliva and try-in paste.

Keywords: Bond strength; contamination; saliva; zirconia; lithium disilicate.
\end{abstract}

\section{Introduction}

The pursuit for restorations that mimic nature is more evident than ever. Ceramics are widely used in dentistry due to their ability to mimic the optical characteristics of enamel and dentine as well as for their biocompatibility and chemical durability [1]. The development of all-ceramic restorations and evolution of luting agents are making cementation of dental restorations stronger and more predictable [2]. At the same time a myriad of combinations between material and cement options make a simple task more complex, with diverse steps. The achievement of good bonding is sometimes essential for the survival and an all-ceramic restoration because high retention, better marginal adaptation. The achievement of proper bonding is essential for the survival of an all-ceramic restoration, as a result of a precise marginal adaptation associated with adequate bonding cementation, which prevents microleakage, and increase fracture resistance of the restored tooth and the restoration $[3,4]$.

Superior physical properties, biocompatibility, and esthetics have made zirconium oxide ceramics (zirconia) a popular high-strength ceramic coping and framework material [5]. Reliable bonding of zirconia ceramic was reportedly obtained by mechanical retention and chemical bonding of luting cement to the ceramic substrate [4]. Zirconia's acid resistance makes it unresponsive to common etching and silanization procedures, which makes establishing a strong and stable bond to resin luting agents a clinically challenging protocol [6]. The risk of bond failure further intensifies with any contamination on the cementation surfaces and insufficient removal of the contaminants following intraoral try-in procedures [7-9]. Once a restoration is received from the laboratory, it undergoes an initial inspection by the dentist which is followed by a series of events including, removal of temporary restoration, cleaning of the cavity/prepared tooth, try-in of the restoration (usually pretreated in the lab), cleaning the restoration after try-in and bonding of the restoration. While the majority of the bonding process is controlled by the practitioner, laboratory technicians perform some of the steps, like etching or abrasive particles blasting, which are described as pretreatment of the restoration. Those restorations with enhanced surface for bonding will then be tried in and sometimes adjusted by the clinician. During the try-in phase, the restoration comes in contact with saliva, blood, and/or try-in pastes. This process can lead to contamination of 


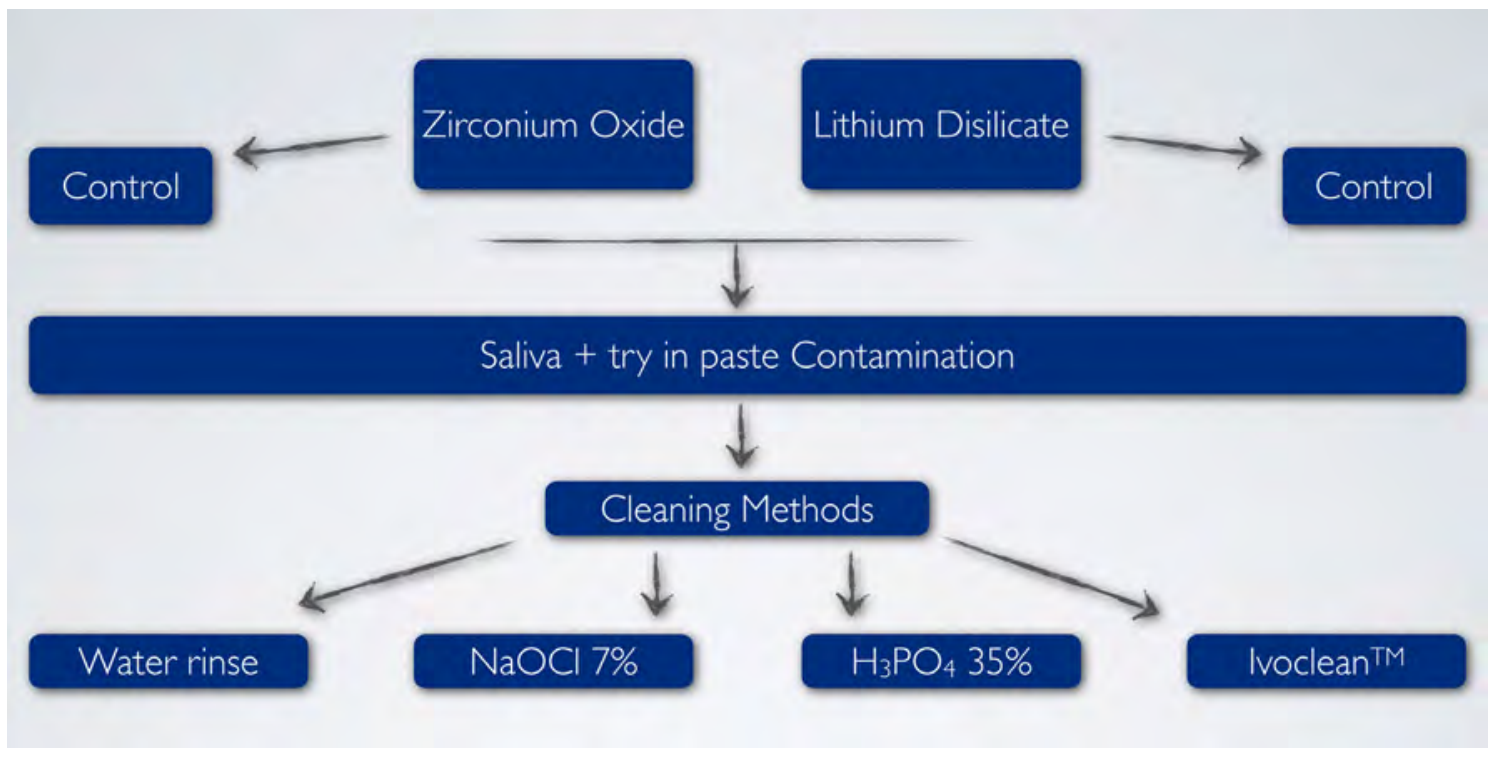

I Figure 1. Experimental design.

the internal surface of the restoration which could eventually compromise the bonding process during the seating of the restoration [6,7,9-11]. Some of the commonly used decontamination methods for restoration surfaces include scrubbing the surface with acetone, application of $37 \%$ phosphoric acid, immersing in $96 \%$ isopropanol, cleaning with $70 \%$ ethanol, airborne-particle abrasion, application of $2 \%$ chlorhexidine, or $5 \%$ sodium hypochlorite and water rinsing $[10,12,13]$. In addition to these products, a universal cleaning agent (Ivoclean; Ivoclar Vivadent AG, Schaan, Liechtenstein) is also available for the extraoral cleaning of ceramic and metal restorations. It is a non-toxic cleaning agent consisting of an alkaline suspension of zirconium dioxide particles, which tend to absorb and bond to phosphate contaminants and helps in surface decontamination $[7,12,14]$. Although, the effect of various cleaning agents/solutions on decontamination of saliva affected all ceramic restorations has been evaluated $[7,9,10,14-21]$, there is no clear protocol on the use of these agents. Also, the available literature is still inconclusive on the decontamination protocol for all ceramic restorations contaminated by both saliva and try-in pastes [11]. Therefore, the purpose of this bench study was to evaluate the bond strength of a resin-based cement to two commercial materials used for all ceramic restorations, IPS e.max ZirCAD and IPS e.max CAD after the contamination with saliva and try in paste and subsequent cleaning with $35 \%$ phosphoric acid or universal cleaning agent, or $7 \%$ Sodium Hypochlorite or simple water rinse. The null hypothesis was that there will be no difference in the bond strength between the resin cement and the ceramic materials after decontamination of the ceramic materials with the four methods used.

\section{Materials and Methods}

The experimental design is shown in Fig. 1. Ten samples for each group were fabricated as follows. IPS e.max ZirCAD (yttrium-stabilized zirconium oxide, Ivoclar Vivadent AG, Schaan, Liechtenstein)

blocks were sectioned to create $10 \times 15 \times 3 \mathrm{~mm}$ samples IsoMet 1000 Buehler) at 150 RPM with Cool 3 cutting fluid lubricant (Buehler, Lake Bluff, IL, USA). The samples were later sintered using a Sintramat (Ivoclar Vivadent AG, Schaan, Liechtenstein) sintering oven. The samples were placed in the firing saggar with sintering beads. The saggar was loaded to the firing chamber at room temperature. The P1 program was used and the sintering was done automatically for 8 hours with a maximum temperature of $1500^{\circ} \mathrm{C}$. The furnace could only be opened after the temperature dropped below $97^{\circ} \mathrm{C}$. After removal the saggar was allowed to cool to room temperature. IPS e.max CAD lithium metasilicate blocks (Ivoclar Vivadent AG, Schaan, Liechtenstein) were sectioned to create $10 \times 15 \times 3 \mathrm{~mm}$ samples. The samples were crystalized according to the manufacture instructions using the Programat P500 furnace (Ivoclar Vivadent AG, Schaan, Liechtenstein). The samples were placed in the furnace using a firing plate without any glaze application since the idea was to simulate the intaglio of the restoration. For crystallization, Sintramat's preloaded program for e.max CAD was used without altering any parameters. After crystallization, all samples were embedded in auto-polymerized acrylic resin (Acratray Blue, Zahn Dental, NY, USA) using an Ultradent 15-hole mold leaving one of the surfaces exposed. The exposed surface was ground with a silicon carbide paper in a polishing station with abundant water cooling to 240 grit size. For the zirconium oxide ceramic, the test surfaces were blasted with aluminum oxide 50 microns at 1 bar. The lithium disilicate ceramic samples were etched for 20 seconds with a $5 \%$ hydrofluoric acid gel (IPS ceramic Etching Gel, Ivoclar Vivadent AG, Schaan, Liechtenstein), rinsed with a water spray for 20 seconds and thoroughly dried with compressed air. One group with 10 samples for each material was not contaminated before bonding. Unstimulated human saliva was collected from one of the researchers that had withdrawn for eating or drinking one-hour prior the collection. Saliva and try-in paste (Variolink II tryin paste, Ivoclar Vivadent AG, Schaan, Liechtenstein) 


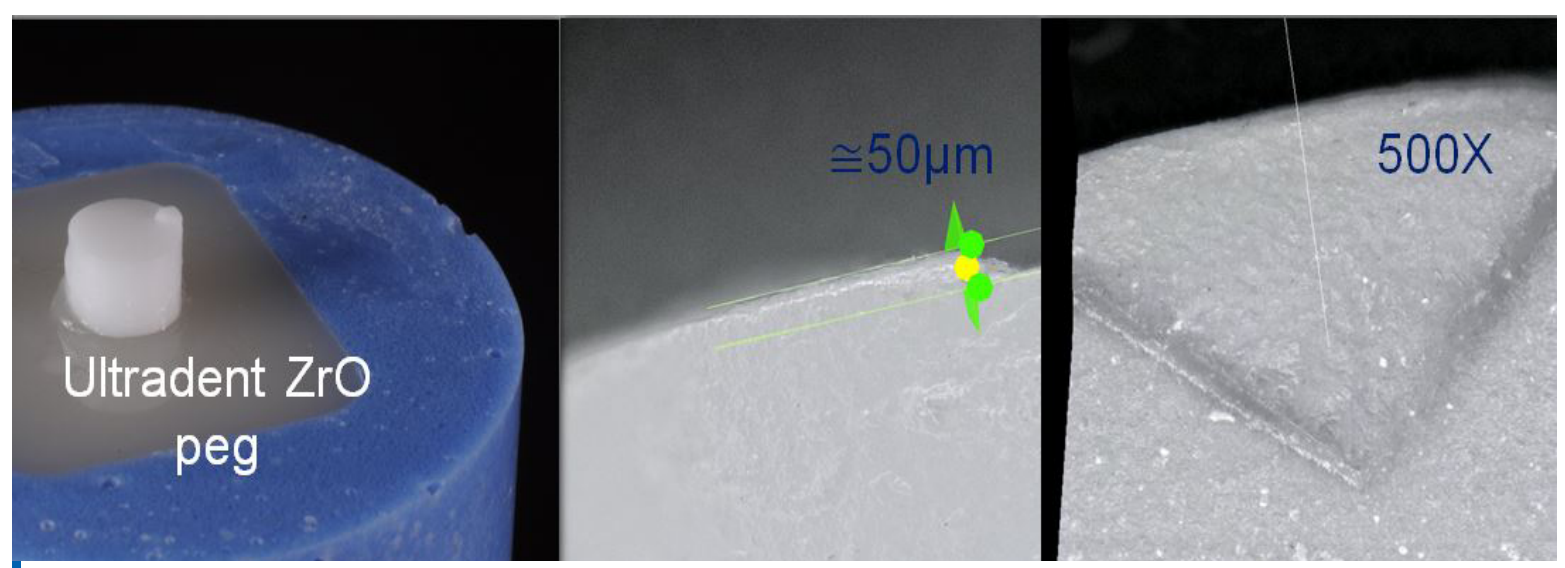

Figure 2. Test set-up for evaluation of shear bond strength.

were applied to the samples. A plastic disc was used to apply pressure over the samples to simulate a crown try-in. After the contamination with saliva and try-in paste all test samples were rinsed with water for 20 seconds and air-dried.

The samples were divided in 5 groups with 10 samples each for both materials, e.max ZirCAD (EMZ) and e.max CAD (EMC):

Group 1 (control group) - No contamination before bonding

Test groups - Saliva/try-in paste contamination with different cleaning methods:

Group 2: Water rinse

Group 3: Water rinse + Cleaning with NaOCL 7\% for 30 seconds followed by air-water rinse

Group 4: Water rinse + Cleaning with $\mathrm{H}_{3} \mathrm{PO}_{4} 35 \%$ for 30 seconds followed by air-water rinse

Group 5: Water rinse + Cleaning with Ivoclean for 30 seconds followed by air-water rinse

Zirconium oxide cylinders (Ultradent, UT, USA) designed with four $50 \mu \mathrm{m}$ pegs (Fig. 2) that defined the thickness of the cement layer were cemented to the samples. The Zirconium oxide cylinders were blasted with aluminum oxide 50 microns at 1 bar and a primer was applied (Zirconia Bond I, Signum). All the samples were treated with an all-purpose primer for 60 seconds (Monobond Plus, Ivoclar Vivadent AG, Schaan, Liechtenstein) prior to the cementation with Multilink Implant cement (Ivoclar Vivadent AG, Schaan, Liechtenstein) without light activation.

After cementation, the samples were placed in a deionized water bath at $37^{\circ} \mathrm{C}$ for $24 \mathrm{~h}$ hours after which they were subjected to shear forces using an Ultradent jig at a crosshead speed of $0.5 \mathrm{~mm} / \mathrm{min}$ with a universal testing machine (Instron, Norwood, MA, USA) to test for bond strength (Fig. 2). The mode of failure (cohesive, adhesive, or mixed) was examined under an optical microscope with 100x and 300x magnification (Keyence VHX-700F series). For the statistical analysis, ANOVA and Tukey's post hoc tests were used to find differences between the cleaning methods with the help of SAS software. The statistical significance was set at $p<0.05$.

\section{Results}

The shear bond strengths for the EMZ samples are shown in Table 1 and Fig. 3. The difference between various groups was not statistically significant $(p=$
Table 1. Shear bond strengths (MPa) for a max. ZirCAD (EMZ) samples.

\begin{tabular}{lcc}
\hline & Mean & Standard Deviation \\
\hline Control & 7.36 & 6.48 \\
EMZ-W & 9.96 & 6.62 \\
EMZ-HC & 8.14 & 5.31 \\
EMZ-PA & 12.95 & 7.96 \\
EMZ-IC & 9.10 & 5.30 \\
\hline
\end{tabular}

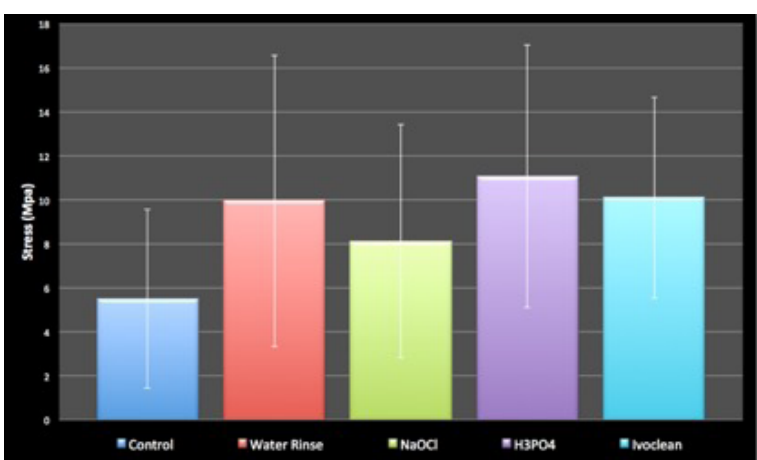

Figure 3. Shear bond strength values for IPS e.max ZirCAD samples for test and control groups.

I Table 2. Shear bond strengths (MPa) for EMC samples.

\begin{tabular}{lcc}
\hline & Mean & Standard Deviation \\
\hline Control & 4.65 & 3.72 \\
EMC-W & 6.78 & 5.30 \\
EMC-HC & 7.99 & 5.60 \\
EMC-PA & 12.28 & 7.22 \\
EMC-IC & 9.45 & 5.96 \\
\hline
\end{tabular}

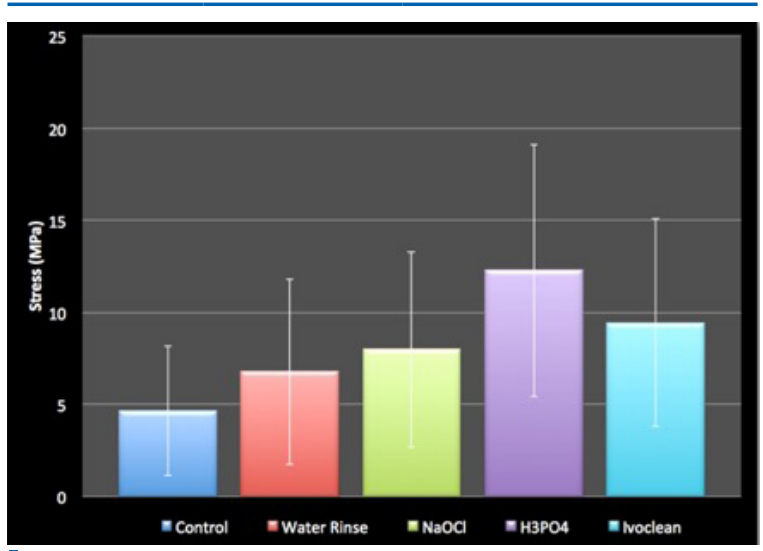

Iigure 4. Shear bond strength values for IPS e.max CAD samples for test and control groups. 

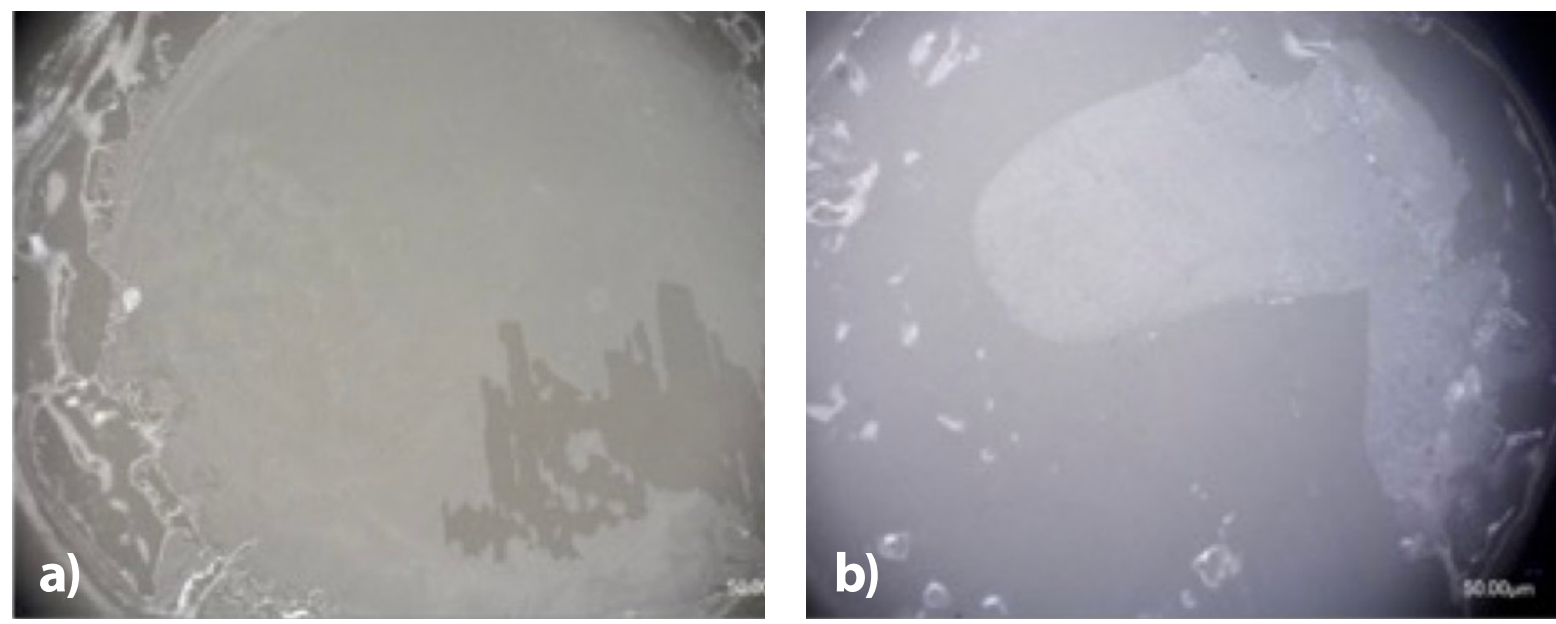

I Figure 5. Microscopic evaluation of failure modes: a) Failure at test ceramic surface; b) Adhesive failure

c) Failure at the peg interface.
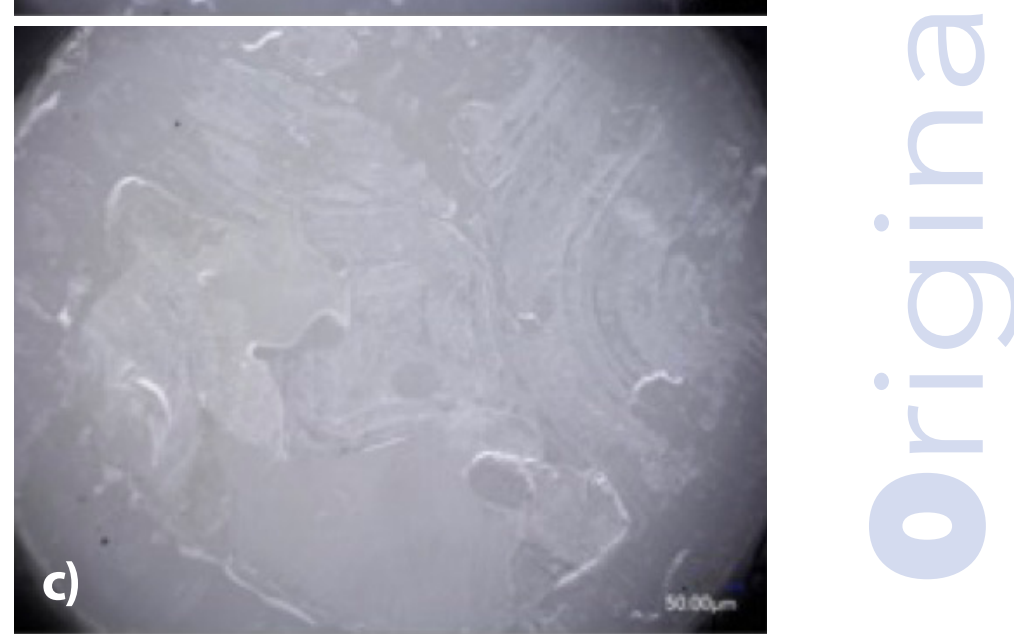

0.419). The shear bond strengths for the EMC samples are shown in Table 2 and Fig. 4.

Group 4 showed the highest shear bond strength. The initial analysis showed statical differences in between the treatment groups $(p=0.028)$.

The Tukey's test confirmed that only the difference between the control and the $\mathrm{H}_{3} \mathrm{PO}_{4}$ means were significantly different $(\mathrm{p}<0.05)$.

The microscopic analysis failed to find any cohesive failures in the test ceramic or the pegs (Fig. 5).

Mixed failures in the tested ceramic interface (63\%); mixed failures with adhesive failures in both side (34\%); mixed failures predominant in the peg interface (3\%).

\section{Discussion}

The present study evaluated the shear bond strengths of saliva and try-in paste contaminated lithium disilicate and zirconia samples subjected to different cleaning regimes. All the cleaning regimens employed in this study showed positive effects on the shear bond strength values. The treatment with phosphoric acid showed the highest values which were significantly better than control for the lithium disilicate samples $(p<0.05)$. The advancement in bonding technology is probably the great contributor for the high success of ceramic restorations, but the technique can be very sensitive. Salivary contamination comes into play when the restorations are tried-in for fit intraorally. The saliva

proteins can be absorbed on the tooth surface as well as the restorative materials [12]. It has been reported previously that the elimination of this saliva or try-in paste contamination is essential to improve the longterm durable ceramic bonding $[8,9,18]$.

All the cleaning methods used in the current study were able to eliminate the negative effects of saliva and try-in paste contamination on zirconia as measured with shear bond strengths. Ivoclean and sodium hypochlorite have been shown to be effective in removing the effects of salivary contamination on zirconia in previous studies $[7,16,18,20]$. Zirconia has a strong adsorption potential to the salivary phosphoproteins which leads to contamination when it comes in contact with saliva [16]. Ivoclean consists of zirconia particles, which, when brought in contact with contaminated zirconia, help absorb the phosphoproteins from its surface, which are then washed away during subsequent rinsing [20,22].

Interestingly, cleaning the zirconia surface with phosphoric acid showed not higher bond strength than control uncontaminated surfaces in this study. It has been reported previously that phosphoric acid successfully removes carbon-based contaminants but may leave a residue of phosphor-based contaminants on the zirconia surface [23]. These phosphor-based contaminants compete with the binding sites on the primer and lead to reduce bond strengths for saliva contaminated samples [16]. On the other hand, phosphoric acid proved to be an effective cleaning agent for zirconia samples contaminated with a 
combination of saliva and dental stone or saliva alone [23]. The values observed with phosphoric acid in our study could be due to the duration of time of its application, which was 30 seconds as compared to 60 seconds in the previous study [16], which could have minimized the phosphor-based contaminant residue on the zirconia surface. Nonetheless, this finding needs further exploration in future studies. Cleaning with phosphoric acid showed a significant improvement in shear bond strength when compared to uncontaminated control lithium disilicate samples. This finding is similar to the results from previous studies [11,14]. Klosa et al. tested the effect of various cleaning agents of lithium disilicate samples contaminated with saliva and silicone disclosing paste [14]. The authors found that both hydrofluoric acid and phosphoric acid were significantly better in improving bond strengths for saliva contaminated samples, although only hydrofluoric acid was able to achieve significantly higher bond strengths with saliva and silicone paste contamination. Interestingly, the samples were only visually inspected after silicone paste contamination and not cleaned with air/water which might have led to the abovementioned results. Nonetheless, the significantly higher bond strengths observed with phosphoric acid in our study shows that it is an effective way to clean lithium disilicate samples contaminated with saliva and try-in paste.

No cohesive failures were observed in this study. All the failures were mixed with a majority of them being either on the test ceramic interface or mixed adhesive failures on both sides suggesting that shear stresses were applied on the adhesive interface. More detailed results could have been observed with the use scanning electron microscopy at a higher magnification as compared to the low magnification of optical microscopy used in this study.

This study used shear bond strength as a measure of effectiveness of various cleaning agents on ceramic samples contaminated with saliva and try-in paste. Both shear and tensile bond strength values have been used in the literature to measure ceramicresin bond $[7,14,6,20,24]$. For a test to measure the bond strength values between an adherent and a substrate accurately, it is crucial that the bonding interface should be the most stressed region, regardless of the test methodology being employed [16]. Although, the microtensile test allows better specimen alignment and a more homogeneous stress distribution, during cutting procedures the adhesive joint may suffer from early debonding, yielding to high numbers of pretest failures, especially with a zirconia substrate [25]. Shear tests have been criticized for the development of nonhomogeneous stress distributions in the bonded interface, but they can be helpful in ranking materials or systems rapidly which could then be tested with more sophisticated methods. For high strength materials like zirconia, specimen preparation for microtensile test could result in more premature failures and defects in the bonded interface [25]. Therefore, SBS seems to be the choice for such specimens and was used for analysis in the present study.

The shear bond strength values observed in the current study are comparatively lower when compared to some studies $[7,16,21,23]$ and comparable to others [18]. Some of the differences in the numbers could be accounted due to different materials used for bonding the ceramic surfaces. Another reason could be the slight diameter mismatch between the pegs which were bonded to the ceramic samples and the notch inside the head of the shear tool on the testing machine as shown in Fig. 2. This could have led to excessive forces on the pegs during the shear test resulting in the observed lower values.

\section{Conclusion}

Within the limitations of the study the following inference could be made:

The cleaning methods used in the current study were able to improve the bond strengths of saliva and try-in paste contaminated zirconia samples to be comparable to the samples without contamination. Treatment with phosphoric acid was able to significantly increase the bond strength of lithium disilicate samples contaminated with saliva and tryin paste.

\section{Author Contributions}

LG:Idea, experimental design, performed the experiment, wrote initial manuscript. HA: wrote final manuscript, proofread manuscript, WM: contribution with literature review, discussion and proofread manuscript.

\section{Acknowledgement}

The authors thank Ivoclar Vivadent for donating the materials.

\section{References}

1. Kelly JR, Benetti P. Ceramic materials in dentistry: historical evolution and current practice. Aust Dent J. 2011;56 Supp 1:84-96.

[CrossRef] [PubMed] Google Scholar Scopus

2. Conrad HJ, Seong WJ, Pesun IJ. Current ceramic materials and systems with clinical recommendations: a systematic review. J Prosthet Dent. 2007;98(5):389-404.

[CrossRef] [PubMed] Google Scholar Scopus

3. Addison O, Marquis PM, Fleming GJ. Quantifying the strength of a resin-coated dental ceramic. J Dent Res. 2008;87(6):542-547. [CrossRef] [PubMed] Google Scholar Scopus

4. Blatz MB, Sadan A, Kern M. Resin-ceramic bonding: a review of the literature. J Prosthet Dent. 2003;89(3):268-274. [CrossRef] [PubMed] Google Scholar Scopus

5. Denry I, Kelly JR. State of the art of zirconia for dental applications. Dent Mater. 2008;24(3):299-307. [CrossRef] [PubMed] Google Scholar Scopus

6. Blatz MB, Chiche G, Holst S, Sadan A. Influence of surface treatment and simulated aging on bond strengths of luting agents to zirconia. Quintessence Int. 2007;38(9):745-753. PubMed] Google Scholar Scopus

7. Aladag A, Elter B, Comlekoglu E, et al. Effect of different cleaning regimens on the adhesion of resin to salivacontaminated ceramics. J Prosthodont. 2015;24(2):136-145. [CrossRef] [PubMed] Google Scholar Scopus

8. Quaas AC, Yang B, Kern M. Panavia F 2.0 bonding to contaminated zirconia ceramic after different cleaning procedures. Dent Mater. 2007;23(4):506-512. [CrossRef] [PubMed] Google Scholar Scopus

9. Yang B, Wolfart S, Scharnberg M, et al. Influence of contamination on zirconia ceramic bonding. J Dent Res. 2007;86(8):749-753.

[CrossRef] [PubMed] Google Scholar Scopus 
10. Nejatidanesh F, Savabi O, Savabi G, Razavi M. Effect of cleaning methods on retentive values of saliva-contaminated implant-supported zirconia copings. Clin Oral Implants Res. 2018;29(5):530-536

[CrossRef] [PubMed] Google Scholar Scopus

11. Prata RA, de Oliveira VP, de Menezes FC, et al. Effect of 'Try-in' paste removal method on bond strength to lithium disilicate ceramic. J Dent. 2011;39(12):863-870.

[CrossRef] [PubMed] Google Scholar Scopus

12. Yang B, Lange-Jansen HC, Scharnberg M, et al. Influence of saliva contamination on zirconia ceramic bonding. Dent Mater. 2008;24(4):508-513.

[CrossRef] [PubMed] Google Scholar Scopus

13. Aboushelib MN, Kleverlaan CJ, Feilzer AJ. Microtensile bond strength of different components of core veneered all-ceramic restorations. Part Il: Zirconia veneering ceramics. Dent Mater. 2006;22(9):857-863.

[CrossRef] [PubMed] Google Scholar Scopus

14. Klosa K, Wolfart S, Lehmann F, et al. The effect of storage conditions, contamination modes and cleaning procedures on the resin bond strength to lithium disilicate ceramic. J Adhes Dent. 2009;11(2):127-135.

[PubMed] Google Scholar Scopus

15. Borges ALS, Posritong S, Özcan M, et al. Can cleansing regimens effectively eliminate saliva contamination from lithium disilicate ceramic surface? Eur J Prosthodont Restor Dent. 2017;25(1):9-14

[PubMed] Google Scholar Scopus

16. Feitosa SA, Patel D, Borges AL, et al. Effect of cleansing methods on saliva-contaminated zirconia - an evaluation of resin bond durability. Oper Dent. 2015;40(2):163-171 [CrossRef] [PubMed] Google Scholar Scopus

17. Irmak O, Yaman BC, Orhan EO, et al. Influence of cleaning methods on bond strength to saliva contaminated zirconia. $J$ Esthet Restor Dent. 2018;30(6):551-556.

[CrossRef] [PubMed] Google Scholar Scopus
18. Kim DH, Son JS, Jeong $\mathrm{SH}$, et al. Efficacy of various cleaning solutions on saliva-contaminated zirconia for improved resin bonding. J Adv Prosthodont. 2015;7(2):85-92. [Free PMC Article] [CrossRef] [PubMed] Google Scholar Scopus

19. Pitta J, Branco TC, Portugal J. Effect of saliva contamination and artificial aging on different primer/cement systems bonded to zirconia. J Prosthet Dent. 2018;119(5):833-839. [CrossRef] [PubMed] Google Scholar Scopus

20. Takahashi A, Takagaki T, Wada T, et al. The effect of different cleaning agents on saliva contamination for bonding performance of zirconia ceramics. Dent Mater J. 2018;37(5):734-739.

[CrossRef] [PubMed] Google Scholar Scopus

21. Yoshida K. Influence of cleaning methods on resin bonding to saliva-contaminated zirconia. J Esthet Restor Dent. 2018;30(3):259-264 [CrossRef] [PubMed] Google Scholar Scopus

22. Ishii R, Tsujimoto A, Takamizawa T, et al. Influence of surface treatment of contaminated zirconia on surface free energy and resin cement bonding. Dent Mater J. 2015;34(1):91-97. [CrossRef] [PubMed] Google Scholar Scopus

23. Phark JH, Duarte S Jr, Kahn H, et al. Influence of contamination and cleaning on bond strength to modified zirconia. Dent Mater 2009:25(12):1541-1550. [CrossRef] [PubMed] Google Scholar Scopus

24. Kato T, Masuda Y, Nakamura N, Yoshida A. Association between changes in cortical and jaw motor activities during sleep. Journal of Oral Biosciences. 2012;54(1):5-10. Google Scholar Scopus

25. Valandro LF, Özcan M, Amaral R, et al. Effect of testing methods on the bond strength of resin to zirconia-alumina ceramic: microtensile versus shear test. Dent Mater J. 2008;27(6):849-855

[Full text links] [PubMed] Google Scholar Scopus

\section{Luiz H. GONZAGA}

DDS, MS, Clinical Assistant Professor Department of Oral \& Maxillofacial Surgery, Center for Implant Dentistry College of Dentistry, University of Florida Gainesville, FL, USA

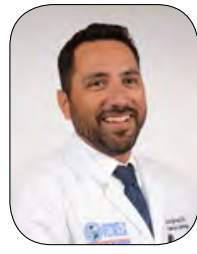

Dr. Luiz H. Gonzaga, DDS, MS graduated from the Catholic University of Brasilia College of Dentistry in 2004. After working in private practice and taking perio/implants CE courses for one year he was accepted for the Implant/Periodontic specialty training graduating in 2009. Dr. Gonzaga was awarded with the ITI scholarship in 2009 and completed his OMFS fellowship the next year. He completed a residency program and Masters in Prosthodontics from the University of Florida in 2014. Currently he is a Clinical Assistant Professor at the University of Florida Center for Implant Dentistry. Dr. Gonzaga is an ITI speaker and Fellow of the International Team for Implantology, a member of the American College of Prosthodontics, and the Academy of Osseointegration.

\section{0ugestions}

\section{What percentage of Hydrofluoric acid was used to etch Lithium Disilicate samples?}
ㅁ. $3.5 \%$;
口b. $5 \%$;
口c. 7\%;
口c. 9.5\%;

\section{Which try-in paste was used?}
口a. Duolink;
ab. Variolink;
口c. Panavia;
ad. Multilink.

3. How long was Ivoclean applied for?

口a. 30 seconds;

ab. 20 seconds;

ac. 15 seconds;

ad. 10 seconds.

\section{How long were samples placed in deionized bath?}

a. 6 hours;

ab. 12 hours;

ac. 24 hours;

ad. 1 week. 